\title{
AUC Infinity Observed Normalized by Body Mass Index
}

National Cancer Institute

\section{Source}

National Cancer Institute. AUC Infinity Observed Normalized by Body Mass Index. NCI Thesaurus. Code C92316.

The observed area under the curve (AUC) extrapolated to infinity divided by the body mass index. 